\title{
Article
}

\section{Dependence of reflectance on angular deposition and film thickness of $\mathrm{ZnS} / \mathrm{Ag}$ nanolayers}

\author{
Edward Bwayo $^{1, *}$, Willy Okullo ${ }^{1}$, Daniel Mukiibi ${ }^{1}$, Denis Okello ${ }^{1}$, Robert Lugolole $^{1}$ and Tumps Winston \\ Ireeta $^{1}$ \\ 1 Department of Physics, School of Physical Sciences, College of Natural Sciences, Makerere University, Uganda. \\ * Correspondence: bwayoedward@gmail.com
}

Received: 16 May 2021; Accepted: 10 November 2021; Published: 30 December 2021.

\begin{abstract}
This paper presents the spectral reflectance of thermally evaporated ZnS/Ag nanostructures. The coating of $\mathrm{ZnS} / \mathrm{Ag}$ nanostructures was performed in two steps while varying the film thickness and deposition angle. Silver metal wire $\left(99.99 \%\right.$ purity) was heated under vacuum at a pressure of $2.5 \times 10^{-5}$ $\mathrm{mBars}$ and deposited on glass slide substrates in the diffusion pump microprocessor vacuum coater (Edwards AUTO 306). Pieces of zinc sulphide ( $99.99 \%$ purity) were heated and deposited to the glass slides previously coated with silver to form the $\mathrm{ZnS} / \mathrm{Ag} /$ glass composite. The optical reflectance of the samples was studied by the UV/Vis/NIR spectrometer (Perkin Elmer Lambda 19) with UV-WinLab software. The reflectance was measured at angles of incidence between $15^{\circ}$ and $75^{\circ}$. Spectrophotometric studies showed that reflectance decreased with decrease in film thickness and decreased with increase in deposition angle of silver nanoparticles. The reflectance of $\mathrm{ZnS} / \mathrm{Ag}$ nanostructures decreased with increase in deposition angle of zinc sulphide.
\end{abstract}

Keywords: ZnS/Ag nanostructures; Film thickness; Deposition angle; Reflectance.

\section{Introduction}

$\mathbf{T}$ he reflectance properties of surfaces of optical components in several devices in use today require careful tailoring to meet the requirements of technological advances. Reflective mirrors for use in domestic and industrial housing units in hot climates should have the potential to reflect a high percentage of infrared radiation but transmit a desirable amount of visible light. However, these reflective surfaces are susceptible to environmental degradation. This is a fundamental setback in optical applications. It is very vital for the reflective surfaces to be protected and made resistant to weather and chemicals in the environment $[1,2]$. Most reflective mirrors are coated with metals films such as silver, copper, gold, aluminium to improve there reflective characteristics. These metals at nano-scale have remarkably low optical absorption in the visible region and high reflectance in the infrared region and frequency dependent refractive index [3-5]. The additional technical characteristic of silver at nano-scale is that of high chemical and optical activity with the capacity to fuse with dielectric materials to form hybrid semiconductor layers [6-8].

Nevertheless, whenever materials such as silver, gold, copper, and aluminium are exposed to the environment, they tend to age out due to environmental degradation. They thus have to be protected by coating them with a suitable material in form of a transparent dielectric coating material. A dielectric material is a transparent film which has strong ionic or directed covalent bonds. Most dielectrics are transparent to visible and/or infrared light. When an electromagnetic radiation falls on a dielectric material, it interacts with valency band electrons. The valency band electrons absorb energy and under go electronic transitions to the conduction band. This changes the the optical parameters of the dielectric films $[9,10]$. The change in optical properties can be quantified by solving Maxwell equations at the boundary between different optical media subject to boundary conditions [10]. Dielectrics used for this purpose include zinc oxide, magnesium floride, zinc sulphide, indium tin oxide among others [11,12]. The optical characteristics of zinc oxide, magnesium floride, zinc sulphide, indium tin oxide are among other factors governed by deposition conditions which include deposition pressure, temperature, deposition rate and deposition angle [13]. Other factors like film 
thickness are required when tuning the spectral reflective properties of nanostructured components for optical, electrooptic, telecommunications and architectural applications in energy conservation [14].

The energy efficiency of buildings for residential and industrial storage facilities in most instances is regulated with external cooling mechanisms such as electric powered air conditioners. The cooling systems are very expensive to maintain on the short and long run. The architectural windows and doors are part of the alternative natural cooling options that are cheap to install and maintain. Several buildings are fitted with float glass windows whose spectra properties have not been quantified by any spectrophotometric processes. However, glass panes used on windows should be designed to reflect infrared radiation but at the same time allow a considerable amount of visible light to pass through them. On this note, the optical structural adjustment of the window surface has always not been a simple task to under take [15-17]. Many attempts have been made to modify the optical properties of glass by applying transparent polystyrene or coating the glass surface with transparent dielectric or metallic thin films. During thin films deposition processes, it is vital to control the vapour flux coming from evaporating materials. The evaporating material may reach the substrate normally or at an oblique angle. At normal incident, the vapour flux upon deposition tends to form a relatively uniform homogeneous film. Nevertheless, the growth of very thin films is always accompanied by the formation of atomic islands on the surface of the dielectric [18,19].

However, during oblique deposition, the adhesion of initial particles on the substrate may hinder the direct impact of preceding atoms on the substrate. Along the direction of initially deposited atoms, columns are formed that shadow the incoming vapour atoms from reaching directly to the substrate surface [20,21]. This leads to the formation of columner structures which restrict adatom mobility and surface diffusion of deposited particles. Oblique deposition therefore, produces rough surfaces but also changes film micro-structure [22,23]. Atomic islands are also formed for very thin nanostructures $(<12 \mathrm{~nm})$ [24]. The microstructure may have pores or internal voids that affect the density, optical reflectance, transmittance and optical absorbance of the thin films $[25,26]$.

When an electromagnet radiation is incident on a thin film coated on glass surfaces, it is either transmitted with attenuation or upon reflection may surfer interference effects due multiple reflections from different media interfaces. However, the extent of these effects depend on the values of optical constants, angle of incidence, microstructure and surface roughness of the reflective surface. Additionally, reflectance of a surface may be affected by the relative motion between the Earth and the Sun. The intensity of electromagnetic radiation from the Sun changes with time along side other factors like, location, the Sun angle and solar shading. Hence, it is very important to measure and establish the reflectance values for different angles of incident radiation for every reflecting surface. This information is very important in structural design of fenestration especially transparent windows and doors [27]. Although several attempts have been made to control thermal conductivity through walls and the roof of buildings [28,29], thermal radiation transfer from the ambient through the transparent windows and doors into the building envelope remains one of the biggest challenges in the housing industry. Thus in this paper, the authors present the spectral reflectance of $\mathrm{ZnS} / \mathrm{Ag}$ nanostructures hinged on film thickness, deposition angle and angle of incidence of electromagnetic radiation.

\section{Experimental procedures}

The deposition of $\mathrm{ZnS} / \mathrm{Ag}$ thin films was performed in two steps while varying the film thickness and deposition angle. Silver metal wire $(99.99 \%$ purity) was heated on a refractory tantalum boat under vacuum at a pressure of $2.5 \times 10^{-5} \mathrm{mBars}$ and deposited on glass slide substrates in the diffusion pump microprocessor vacuum coater (Edwards AUTO 306). The heating current was slowly raised to a current of 38 A because silver metal has low melting point of $961^{\circ} \mathrm{C}$. The evaporation rate of $1 \mathrm{nms}^{-1}$ was used. Glass slides were fixed on a rotary holder placed $11 \mathrm{~cm}$ away from the refractory boat vertically above it. The substrate holder together with the glass slide was rotated at an angle $\theta$ about the horizontal so that the vapor is incident at an angle $\theta$ to the substrate normal (the angle between the normal to the substrate and direction of incidence of the evaporated atoms). The setup is shown in Figure 1 below. Three sets of samples of silver films of thickness $4 \mathrm{~nm}$ were deposited at different angles of $\theta=0^{\circ}, 30^{\circ}$ and $60^{\circ}$. This was repeated for each of thickness of 7,10 and $15 \mathrm{~nm}$ onto glass substrate. 


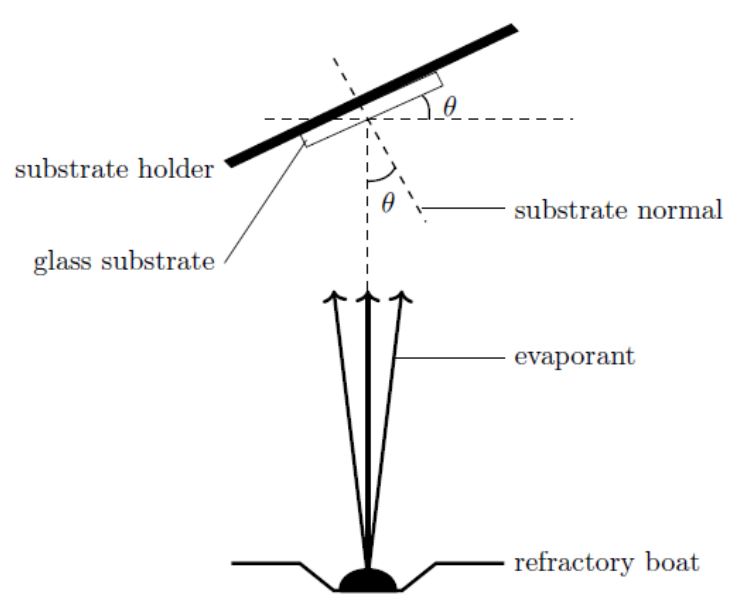

Figure 1. Setup for Vacuum vapour deposition

The pieces of $\mathrm{ZnS}$ (99.99\% purity) were heated in a molybdenum boat with source cover to reduce the spreading of the vapor. Because $\mathrm{ZnS}$ has a high melting point of $1830^{\circ} \mathrm{C}$, the heating current was increased to $56 \mathrm{~A}$. The $\mathrm{ZnS}$ was heated and deposited to film thickness of $4 \mathrm{~nm}$ at vapour incidence angle $\theta=0,30$ and $60^{\circ}$ to the glass slides previously coated with silver to form the $\mathrm{ZnS} / \mathrm{Ag} /$ glass multilayer system shown in Figure 2.

This procedure was repeated for thicknesses 7,10 and $15 \mathrm{~nm}$. The thickness monitor was calibrated separately for each of the materials in the vacuum chamber. The thickness of the films were measured by a thickness monitor connected to a quartz crystal monitoring system placed inside the diffusion chamber [30]. In vacuum vapour deposition, it is very had to produce films that have perfectly smooth surfaces with high homogeneity and uniform thickness. This effect compromises the accuracy of the spectrophotometric results since the measurement of transmittance and reflectance can hardly be done at exactly the same spot on the specimen [31].

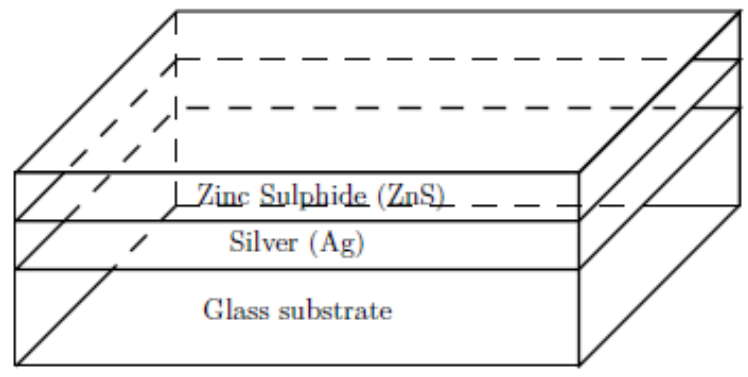

Figure 2. An expanded representation of the $\mathrm{ZnS} / \mathrm{Ag} /$ glass composite

The optical reflectance of the samples were studied by the UV/Vis/NIR spectrometer (Perkin Elmer Lambda 19) with UV-WinLab software. This is a double beam instrument covering the ultraviolet, visible and near infrared spectral wavelength. Baseline measurement using a clean piece of substrate was done. Reflectance was measured at angles of incidence; $15^{\circ}, 30^{\circ}, 45^{\circ}, 60^{\circ}$, and $75^{\circ}$ of the incident radiation to the optical system in the wavelength range of 250 to $2500 \mathrm{~nm}$ [32]. Since it is very had to measure reflectance at normal incidence, the lowest angle of incidence for reflectance measurements was $15^{\circ}$ subject to the limitations of the spectrometer model used [33].

\section{Results and discussion}

\subsection{Effect of thickness and deposition angle on reflectance of $\mathrm{ZnS}(0) / \mathrm{Ag}$ films}

The spectrophotometric measurements on reflectance was analysed on specimens fabricated with different thickness and deposition angles. The reflectance of normally deposited $\mathrm{ZnS}(0) / \mathrm{Ag}(0)$ nanostructures 
was relatively low (ranged between 5\% - 35\%) in the visible range $(400-780 \mathrm{~nm}$ ) of the electromagnetic spectrum followed by a rise in reflectance towards the infrared at about $\lambda=800 \mathrm{~nm}$, Figure 3 (a). The reflectance results showed remarkable interference effects in the infrared region in all the samples. These effects were dependent on the film thickness and wavelength of the electromagnetic radiation. The interference effects ware observed in the infrared region 800 âA̧2200 $\mathrm{nm}$ and the tended to disappear or diminshed as the wavelength approached the the upper edge of the visible spectrum. This observation was also reported in the obliquely deposited $\mathrm{Nb}_{2} \mathrm{O}_{5}$ [34] and $\mathrm{ZnO}$ [35] thin films.

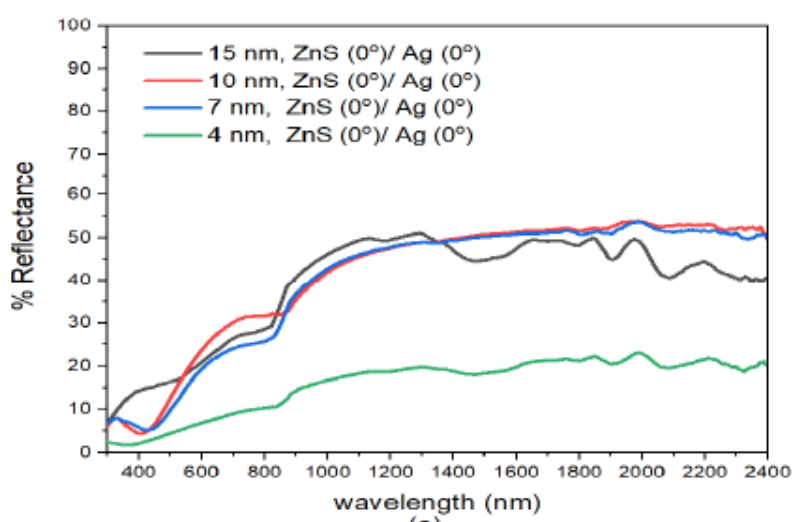

(a)

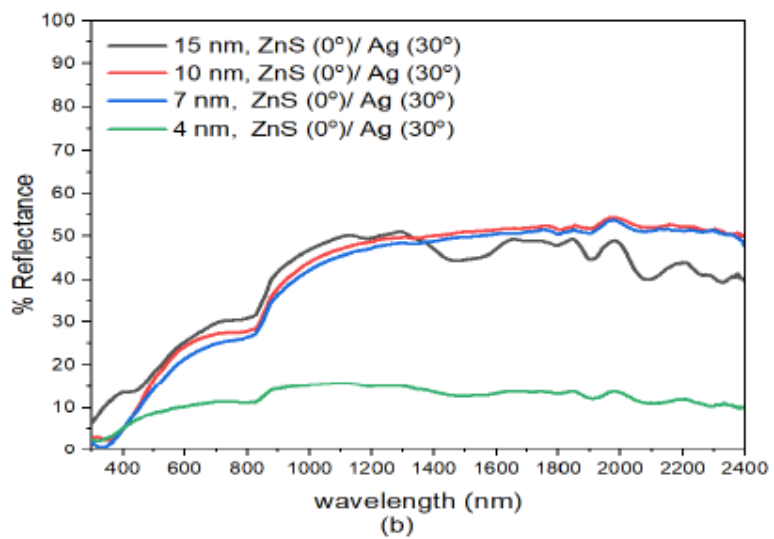

(b)

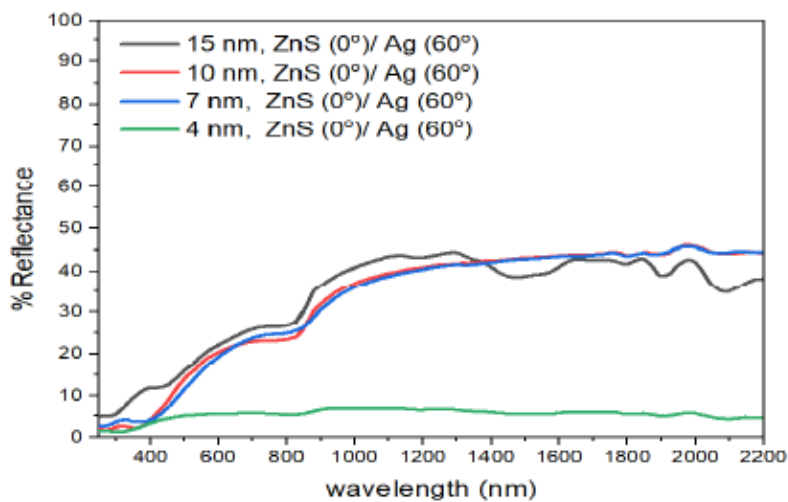

(c)

Figure 3. Effect of thickness and deposition angle of $\mathrm{Ag}$ on reflectance of $\mathrm{ZnS} / \mathrm{Ag}$ nanostructures. The deposition angle of $\mathrm{ZnS}$ films was kept constant at normal incidence, $\left(0^{\circ}\right)$.

The interference effects in the infrared region were more intense in the $(15 \mathrm{~nm}) \mathrm{ZnS}(0) / \mathrm{Ag}(0)$ nanostructures. These effects were as a result of reflection from different optical interfaces of air- $\mathrm{ZnS}, \mathrm{ZnS}-\mathrm{Ag}$, and Ag-glass interfaces [36]. The interference effects infer that the prepared samples were relatively smooth and uniform [37,38]. There was a further rise in reflectance to about $54 \%$ in the infrared region at about $\lambda=1300 \mathrm{~nm}$. It was also observed that the reflectance decreased with decrease in film thickness of $\mathrm{ZnS} / \mathrm{Ag}$ multilayer films Figure 3 (a). However, there was a big drop in reflectance with film thickness from (7 $\mathrm{nm}) \mathrm{ZnS}(0) / \mathrm{Ag}(0)$ to $(4 \mathrm{~nm}) \mathrm{ZnS}(0) / \mathrm{Ag}(0)$. The decrease in reflectance was partly due to decrease in film thickness and formation of atomic islands during the deposition of very thin metal films and dielectric nanostructures $[39,40]$.

For wavelength below $\lambda=400 \mathrm{~nm}$, there were interference minima in reflectance of the samples. These effects according to Wlodarski et al., [41] and Zhou and Liu [42] were as a result of increase in absorption due to interband electronic transitions of the zinc and silver atoms. Thin nanostructures of $(4 \mathrm{~nm}) \mathrm{ZnS}(0) / \mathrm{Ag}(0)$, had very low reflectance values i.e. between $2.6 \%-10.5 \%$ in the visible region and reflectance increased to a maximum value of $22.1 \%$ at $\lambda=2000 \mathrm{~nm}$ in the infrared wavelength as shown in Figure 3 (a).

When the deposition angle of $\mathrm{Ag}$ nanoparticles was increased to $30^{\circ}$ in the $\mathrm{ZnS} / \mathrm{Ag}$ composite i.e. $\mathrm{ZnS}(0) / \mathrm{Ag}(30)$ Figure $3(\mathrm{~b})$, the reflectance decreased progressively as the thickness of $\mathrm{Zn} / \mathrm{Ag}$ films dencreased. The reflectance of $(15 \mathrm{~nm}) \mathrm{ZnS}(0) / \mathrm{Ag}(30)$ in the visible region $(400-800 \mathrm{~nm})$ was between $13 \%$ $-31 \%$. In the infrared region, the reflectance had maximum value of about $50.5 \%$. Highest reflectance values 
were recorded for thin films of $(15 \mathrm{~nm}) \mathrm{ZnS} / \mathrm{Ag}$. This trend was also observed in other thin films of thickness $(7 \mathrm{~nm}) \mathrm{ZnS} / \mathrm{Ag}$ and $(4 \mathrm{~nm}) \mathrm{ZnS} / \mathrm{Ag}$ but with reduced values of reflectance in the in the visible and infrared wavelengths. A significant drop in reflectance was recorded for $(4 \mathrm{~nm}) \mathrm{ZnS} / \mathrm{Ag}$ nanostructures. This was due to increased optical absorption and transmittance of the $(4 \mathrm{~nm}) \mathrm{ZnS} / \mathrm{Ag}$ nanostructures. Additionally, the increase the deposition angle increased film discontinuities and roughness which in turn increased optical absorption due to aggregation of silver islands on the glass substrate $[43,44]$. In a separate study on very thin nanolayers by Hu et al., [45] destructive interference enhances optical absorption and transmittance but suppresses reflectance of the electromagnetic waves. There were interference effects which alternated with decreasing thickness of the $\mathrm{ZnS} / \mathrm{Ag}$ composite and the deposition angle of silver nanoparticles. This had pronounced effects on reflectance of near infrared radiation. On a whole, reflectance decreased with decrease in film thickness and decreased with increase in deposition angle of Ag.

Further increase in deposition angle of $\mathrm{Ag}$ from $\mathrm{ZnS}(0) / \mathrm{Ag}(30)$ to $\mathrm{ZnS}(0) / \mathrm{Ag}(60)$ Figure 3 (c), decreased the reflectance. However, the nanostructure response to reflectance was not so sensitive to the small increase in deposition angle of silver metal films. The reduction in reflectance according to Liedtke et al., [43] was attributed to atomic shadowing that created areas with reduced grain size of silver atoms. This created imperfections in the Ag films. These imperfections generate grain boundaries in the thin films that decreased the reflectance of the thin films. As the number of grain boundaries increases with deposition angle, there is reduction in specular reflection for very thin films due to scattering of incident light. The increase in reflectance at wavelengths $\lambda>800 \mathrm{~nm}$ was related to the increase of the Drude-like absorption in which the amount of voids in the metal phase increases [46].

\subsection{Effect of thickness and deposition angle on reflectance of $\mathrm{ZnS}(30) / \mathrm{Ag}$ films}

The reflectance of obliquely deposited $\mathrm{ZnS}(30) / \mathrm{Ag}(0)$ films presented in Figure 4 (a), can be described from two perspectives. Thus, the reflectance decreased with decrease in film thickness but also the reflectance increased along with the increase in wavelength of electromagnetic radiation.

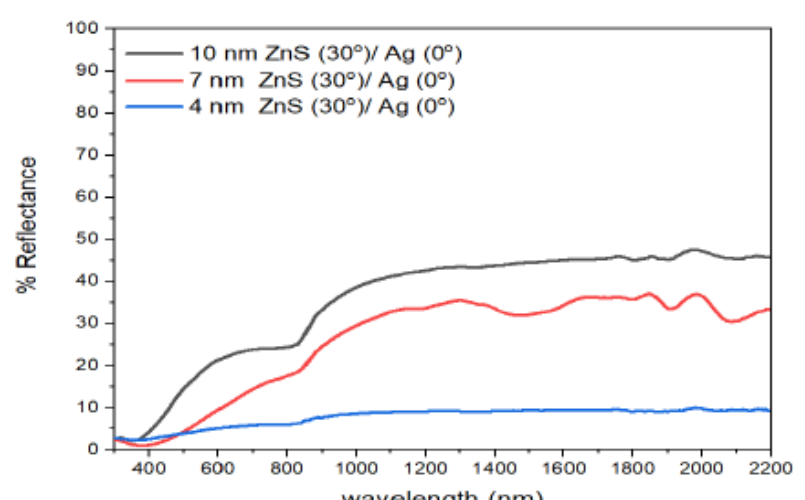

(a)

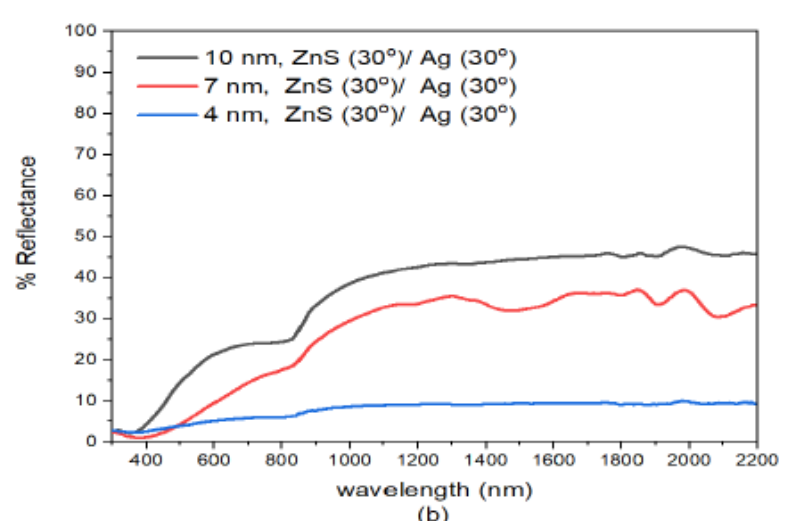

(b)

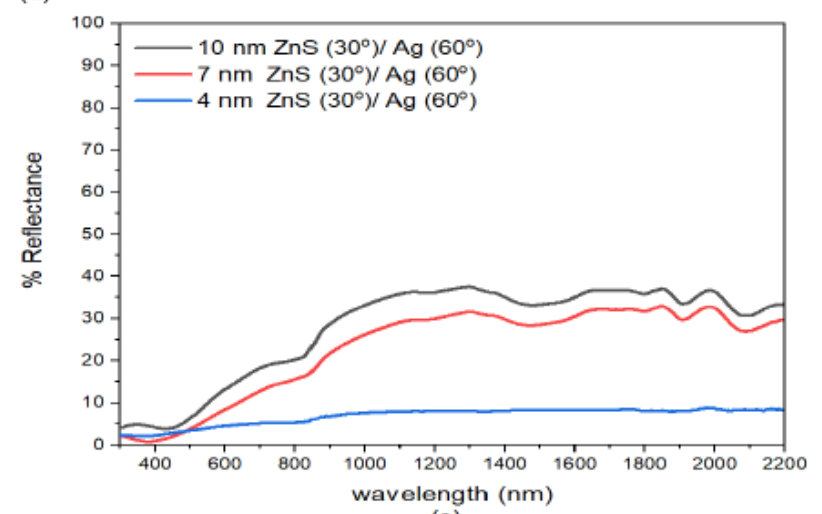

(c)

Figure 4. Effect of thickness and deposition angle of Ag on reflectance of $\mathrm{ZnS} / \mathrm{Ag}$ films. The deposition angle of $\mathrm{ZnS}$ nanoparticles was maintained at $\left(30^{\circ}\right)$ for three deposition angles of Ag nanoparticles. 
On the other hand, the deposition angle of $\mathrm{ZnS}$ had little impact on reflectance in the visible wavelength. The reflectance values in the visible region at about $\lambda=800 \mathrm{~nm}$ were $25.2 \%$ for $(10 \mathrm{~nm}) \mathrm{ZnS}(30) / \operatorname{Ag}(0)$, $18.8 \%$ for $(7 \mathrm{~nm}) \mathrm{ZnS}(30) / \mathrm{Ag}(0)$ and $6.4 \%$ for $(4 \mathrm{~nm}) \mathrm{ZnS}(30) / \mathrm{Ag}(0)$ samples. However, the reflectance in the infrared wavelength decreased with increase in deposition angle of zinc sulphide. At about $\lambda=1800 \mathrm{~nm}$, the reflectance values were $45.8 \%$ for $(10 \mathrm{~nm}) \mathrm{ZnS}(30) / \mathrm{Ag}(0), 37.0 \%$ for $(7 \mathrm{~nm}) \mathrm{ZnS}(30) / \mathrm{Ag}(0)$ and $9.4 \%$ for $(4$ $\mathrm{nm}) \mathrm{ZnS}(30) / \mathrm{Ag}(0)$ samples. This implies that increasing the deposition angle of $\mathrm{ZnS}$ increased the optical absorption in the infrared spectral region.

Reflectance of the samples in Figure 4 (b) decreased with decrease in film thickness of the ZNS/Ag composite. When the deposition angle of $\mathrm{Ag}$ was increased from $(\mathrm{ZnS}(30) / \mathrm{Ag}(0)$ to $(\mathrm{ZnS}(30) / \mathrm{Ag}(30)$, the reflectance of the multilayer was further reduced. This decrease was observed both in the visible wavelengths at about $\lambda=800 \mathrm{~nm}$ was as follows: $24.0 \%$ for $(10 \mathrm{~nm}) \mathrm{ZnS}(30) / \mathrm{Ag}(30), 17.0 \%$ for $(7 \mathrm{~nm}) \mathrm{ZnS}(30) / \mathrm{Ag}(30)$ and $6.3 \%$ for $(4 \mathrm{~nm}) \mathrm{ZnS}(30) / \mathrm{Ag}(30)$. The reflectance values obtained in the infrared wavelengths at $\lambda=1800 \mathrm{~nm}$ were $45.1 \%$ for $(10 \mathrm{~nm}) \mathrm{ZnS}(30) / \mathrm{Ag}(30), 36.5 \%$ for $(7 \mathrm{~nm}) \mathrm{ZnS}(30) / \mathrm{Ag}(30)$ and $9.5 \%$ for $(4 \mathrm{~nm}) \mathrm{ZnS}(30) / \mathrm{Ag}(30)$ specimens. The reflectance values in the infrared region were higher than those in the visible region. The reflectance of $(4 \mathrm{~nm}) \mathrm{ZnS}(30) / \mathrm{Ag}(30)$ was exceptionally very low. This was largely contributed by the small film thickness, the oblique deposition angle of $\mathrm{ZnS}$ and silver thin films and optical absorption by the discontinuous islands of silver formed on glass substrate.

However, as the deposition angle of both $\mathrm{ZnS}$ and $\mathrm{Ag}$ was increased to $\mathrm{ZnS}(30) / \mathrm{Ag}(60)$ Figure 4 (c), the reflectance of $(10 \mathrm{~nm}) \mathrm{ZnS}(30) / \mathrm{Ag}(60),(7 \mathrm{~nm}) \mathrm{ZnS}(30) / \mathrm{Ag}(60)$ and $(4 \mathrm{~nm}) \mathrm{ZnS}(30) / \mathrm{Ag}(60)$ further decreases with film thickness. The reflectance of $(10 \mathrm{~nm}) \mathrm{ZnS}(30) / \mathrm{Ag}(60)$ and $(7 \mathrm{~nm}) \mathrm{ZnS}(30) / \mathrm{Ag}(60)$ samples increased with increase in deposition angle of $\mathrm{Ag}$. The reflectance of $(4 \mathrm{~nm}) \mathrm{ZnS}(30) / \mathrm{Ag}(60)$ was extremely low at an average of $<3 \%$ in the visible region and $<5 \%$ in the infrared wavelength.

\subsection{Variation of thickness and deposition angle on reflectance of $\mathrm{ZnS}(60) / \mathrm{Ag}$ films}

The refleectance of the specimens increased with increase in film thickness. The reflectance was observed to increase from the visible wavelength to infrared wavelength of the electromagnetic spectrum (Figure 5 (a)). Interference effects were observed and alternated with film thickness. The reflectance of (10 $\mathrm{nm}) \mathrm{ZnS}(60) / \mathrm{Ag}(0),(7 \mathrm{~nm}) \mathrm{ZnS}(60) / \mathrm{Ag}(0)$ and $(4 \mathrm{~nm}) \mathrm{ZnS}(60) / \mathrm{Ag}(0)$ in the visible region had maximum values of $29.9 \%, 24.1 \%, 7 \%$ respectively at about $\lambda=800 \mathrm{~nm}$. The reflectance values of $(10 \mathrm{~nm}) \mathrm{ZnS}(60) / \operatorname{Ag}(0),(7$ $\mathrm{nm}) \mathrm{ZnS}(60) / \mathrm{Ag}(0)$ and $(4 \mathrm{~nm}) \mathrm{ZnS}(60) / \mathrm{Ag}(0)$ in the infrared region at $\lambda=1800 \mathrm{~nm}$ were $54.9 \%, 41.9 \%$ and $7.4 \%$ respectively. This was attributed to low deposition angle of Ag though the deposition angle of $\mathrm{ZnS}$ is high. This infers that for these particular samples, the deposition angle of $\mathrm{ZnS}$ has a small effect on reflectance of the $\mathrm{ZnS} / \mathrm{Ag}$ multilayer films. The reflectance of $(4 \mathrm{~nm}) \mathrm{ZnS}(60) / \mathrm{Ag}(0)$ was very low $<5 \%$ both in the visible and infrared spectral regions. In this sample, the most influencing factor on reflectance was the film thickness and discontinuities in the nanostructured - silver films.

When the deposition angle of Ag was increased from $\mathrm{ZnS}(60) / \mathrm{Ag}(0)$ to $\mathrm{ZnS}(60) / \mathrm{Ag}(30)$, (Figure 5 (b)), The reflectance of the samples increased with increase in film thickness. The reflectance values further decreased in the visible as follows: $18.3 \%$ for $(10 \mathrm{~nm}) \mathrm{ZnS}(60) / \mathrm{Ag}(30), 16.6 \%$ for $(7 \mathrm{~nm}) \mathrm{ZnS}(60) / \mathrm{Ag}(30)$ and $5.1 \%$ for $(4$ $\mathrm{nm}) \mathrm{ZnS}(60) / \mathrm{Ag}(30)$. In the infrared regions, reflectance reduced as follows: $37.7 \%$ for $(10 \mathrm{~nm}) \mathrm{ZnS}(60) / \mathrm{Ag}(30)$, $27.4 \%$ for $(7 \mathrm{~nm}) \mathrm{ZnS}(60) / \mathrm{Ag}(30)$ and $6.0 \%$ for $(4 \mathrm{~nm}) \mathrm{ZnS}(60) / \mathrm{Ag}(30)$. Interference effects observed along the entire electromagnetic spectrum. This trend is not observed in the $(4 \mathrm{~nm}) \mathrm{ZnS}(60) / \mathrm{Ag}(30)$ multilayer film and its reflectance values are below $6 \%$ in the visible region. Interference effects were observed to diminish since much of the light was either absorbed or transmitted by the $\mathrm{ZnS} / \mathrm{Ag}$ multilayer nanostructures.

The reflectance of the obliquely deposited $\mathrm{ZnS}(60) / \mathrm{Ag}(60)$ samples decreased with decrease in film thickness as shown in Figure 5 (c). The increase in deposition angle of silver further decreased reflectance in the visible region. Interference effects are intense in the $(10 \mathrm{~nm}) \mathrm{ZnS}(60) / \mathrm{Ag}(60),(7 \mathrm{~nm}) \mathrm{ZnS}(60) / \mathrm{Ag}(60)$ and $(4 \mathrm{~nm}) \mathrm{ZnS}(60) / \mathrm{Ag}(60)$ nanostructures. The reflectance values in the visible wavelength for (10 $\mathrm{nm}) \mathrm{ZnS}(60) / \mathrm{Ag}(60),(7 \mathrm{~nm}) \mathrm{ZnS}(60) / \mathrm{Ag}(60)$ and $(4 \mathrm{~nm}) \mathrm{ZnS}(60) / \mathrm{Ag}(60)$ mulitlayers were $17 \%, 13.7 \%$ and $10.5 \%$ respectively. In the infrared region, the reflectance of $(10 \mathrm{~nm}) \mathrm{ZnS}(60) / \mathrm{Ag}(60)$ and $(7 \mathrm{~nm}) \mathrm{ZnS}(60) / \mathrm{Ag}(60)$ nanolayers increased to $31 \%$ and $25.1 \%$ respectively. 


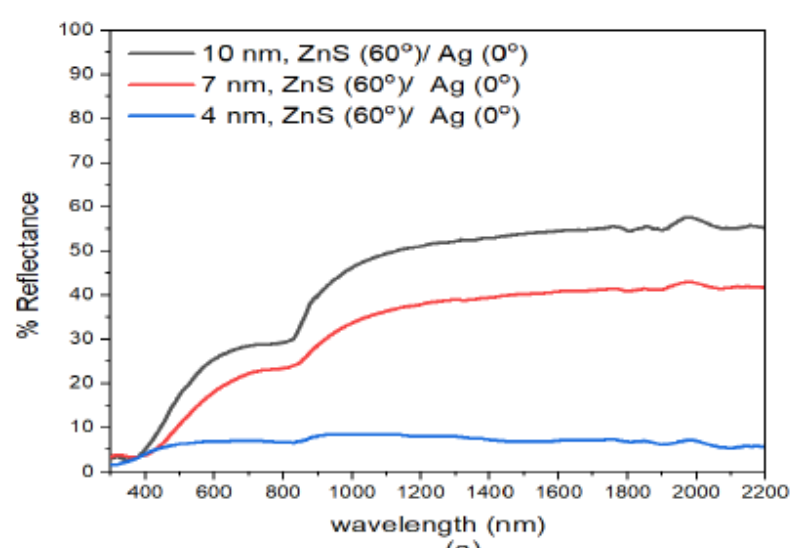

(a)

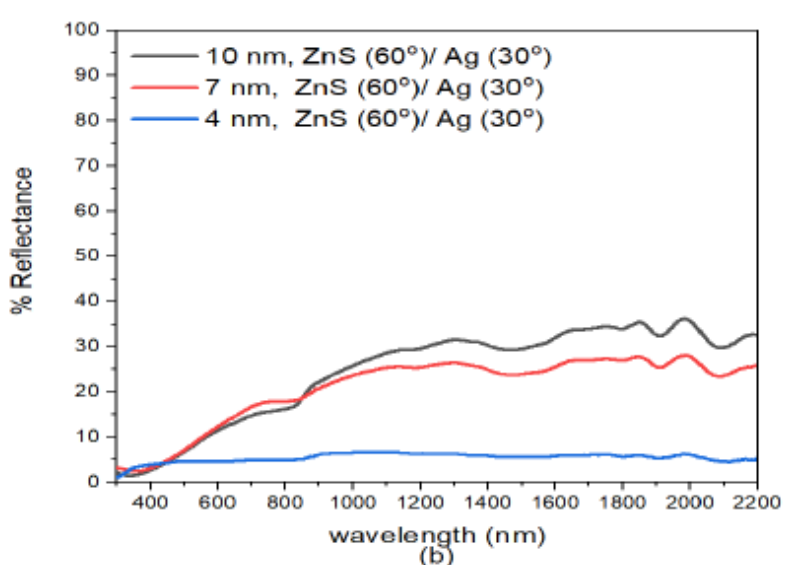

(b)

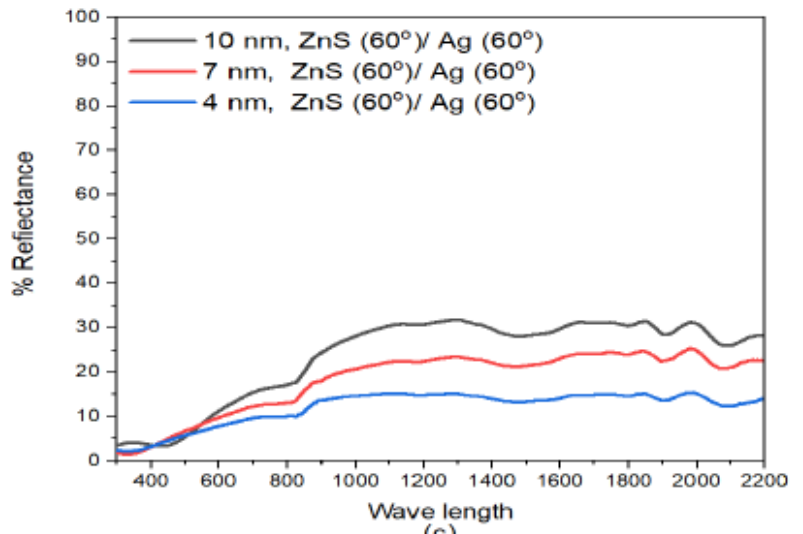

(c)

Figure 5. Effect of thickness and deposition angle of Ag on reflectance of $\mathrm{ZnS} / \mathrm{Ag}$ nanastructures when $\mathrm{ZnS}$ was deposited at $\left(60^{\circ}\right)$ to the substrate normal

\subsection{Effect of angle of incident radiation and deposition angle on reflectance of $(10 \mathrm{~nm}) \mathrm{ZnS} / \mathrm{Ag}(0)$ films}

Generally, reflectance increased from the visible towards the infrared wavelengths in the entire electromagnetic spectrum Figure 6 (a). The reflectance of electromagnetic radiation for normally deposited films i.e. $\mathrm{ZnS}(0) / \mathrm{Ag}(0)$, increased from $i=15^{\circ}$ to $i=30^{\circ}$. The reflectance then decreased progressively from $i=45^{\circ}$ to $i=75^{\circ}$. Reflection peaks were observed at $700 \mathrm{~nm}$ for different angles of incidence. For $i=15^{\circ}$, the peak was observed at $36.8 \%$. And for $i=30^{\circ}, 45^{\circ}, 60^{\circ}$ and $75^{\circ}$ the peaks were at $52.3 \%, 22.1 \%$, and $16.6 \%$ respectively. At $\lambda>800 \mathrm{~nm}$, the reflectance peaks were obtained in the range of $\lambda=1100-1300$ $\mathrm{nm}$. In the infrared wavelengths, very low reflectance values $(<35 \%)$ were recorded at $i=75^{\circ}$. The decrease in reflectance for angles of incidence $i=45^{\circ}$ to $75^{\circ}$ was due to high attenuation and optical absorption of the infrared light by the discontinuous nanolayers. However, interference effects were visible in the entire spectrum. In the event that this material was to be adopted for use as a window pane, then the angle of inclination of the window pane to the direction of incident sun light has to be determined for minimum or enhanced reflectance.

When the deposition angle of $\mathrm{ZnS}$ was increased from $\mathrm{ZnS}(0) / \mathrm{Ag}(0)$ to $\mathrm{ZnS}(30) / \mathrm{Ag}(0)$ Figure 6 (b), there was a slight decrease in reflectance both in the visible and infrared wavelength. This implies that increasing the deposition angle of $\mathrm{ZnS}$ decreased the reflectance of the $\mathrm{ZnS} / \mathrm{Ag}$ nanofilms. Comparatively, these results were lower than those obtained in Figure 6 (a). At $\lambda=720 \mathrm{~nm}$, the peak reflectance values at $i=30^{\circ}, 45^{\circ}, 60^{\circ}$ and $75^{\circ}$ were $28.0 \%, 59.7 \%, 22.9 \%, 21.8 \%$, and $17.0 \%$ respectively. Reflectance then started to increase at $\lambda=800$ $\mathrm{nm}$ towards the infrared spectral region. Very strong interference effects were observed in the infrared region.

Further increase in the deposition angle of $\mathrm{ZnS}$ from $\mathrm{ZnS}(30) / \mathrm{Ag}(0)$ to $\mathrm{ZnS}(60) / \mathrm{Ag}(0)$ Figure 6(c), the reflectance values increased from the visble wavelength towards the infrared wavelengths. The reflectance peaks moved toward the short wavelength. At $\lambda=660 \mathrm{~nm}$, the peak reflectance values for $i=30^{\circ}, 45^{\circ}, 60^{\circ}$ and $75^{\circ}$ were $29.2 \%, 59.7 \%, 22.9 \%, 21.8 \%$ and $17.0 \%$ respectively. After these peak values, there was a drop in reflectance at the upper edge of the visible spectrum. The reflectance values increased from $i=15^{\circ}$ to $i=30^{\circ}$. The reflectance then decreased from $i=45^{\circ}$ to $i=75^{\circ}$. The reflectance of visible light for which the angle 
of incidence $i=30^{\circ}$, had a maximum value of about $59.7 \%$ at wavelength, $\lambda=660 \mathrm{~nm}$. After this point, reflectance then dropped to about $46 \%$ at wavelength $\lambda=883 \mathrm{~nm}$ and it then increased progressively to about $82 \%$ at $\lambda=2400 \mathrm{~nm}$. The reflectance for $i=15,45,60$ and $75^{\circ}$ in the visible region was quite different from the reflectance whose angle of incidence was $i=30^{\circ}$. However, in the infrared region the reflectance values did not differ so much as the wavelength increased. The low reflectance values revealed that the specimens ware transparent to visible light but highly reflective to infrared light. The interference effects in the infrared region $(\lambda>800 \mathrm{~nm})$ ware minimal compared to those obtained in Figure $6(\mathrm{~b})$.

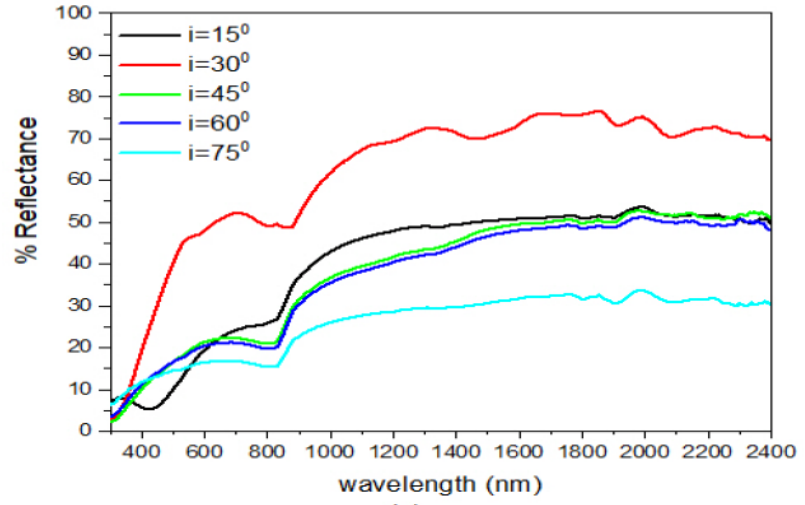

(a)

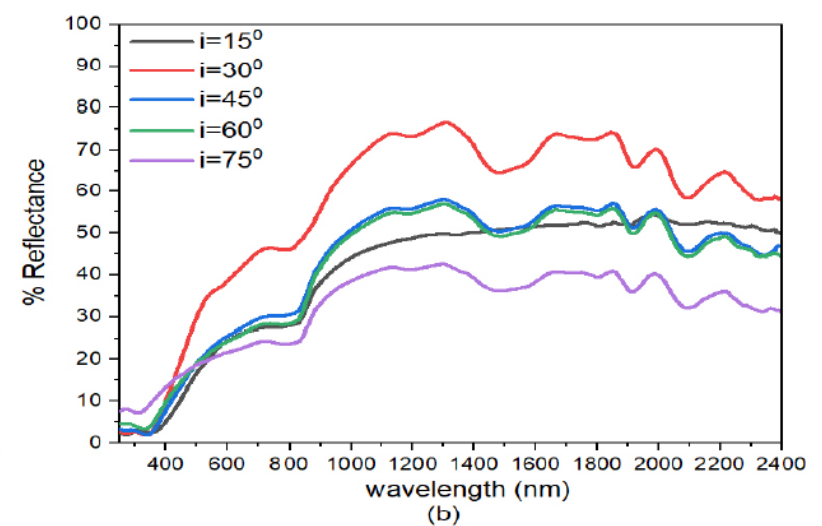

(b)

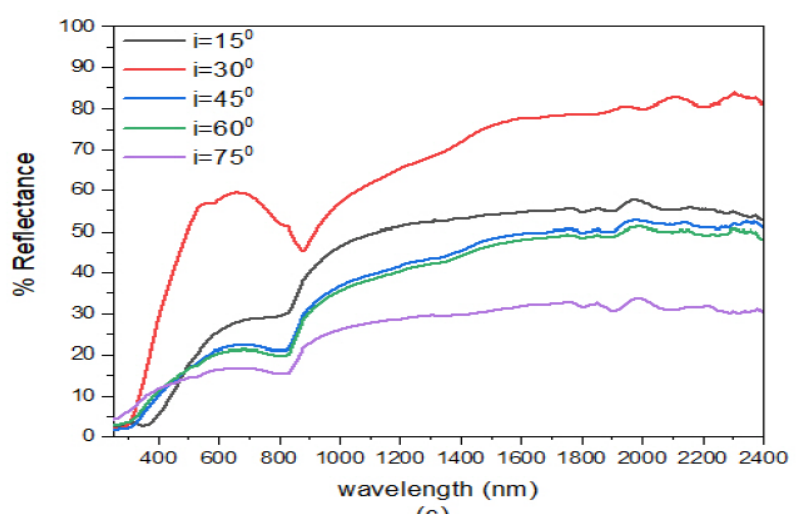

(c)

Figure 6. Effect of angle of incident radiation and deposition angle of $\mathrm{ZnS}$ on reflectance of (10 nm) $\mathrm{ZnS} / \mathrm{Ag}$ films. The silver nanoparticles in the $\mathrm{ZnS} / \mathrm{Ag}$ nanostructure were normally deposited on glass at $\left(0^{\circ}\right)$ followed by $\mathrm{ZnS}$ at different deposition angles; (a) at $\left(0^{\circ}\right)$, (b) at $\left(30^{\circ}\right)$ and (c) at $\left(60^{\circ}\right)$.

\subsection{Effect of angle of incident radiation and deposition angle on reflectance of $(10 \mathrm{~nm}) \mathrm{ZnS} / \mathrm{Ag}(30)$ films}

When the angle of deposition of $\mathrm{ZnS}$ was set to normal angle i.e. $\mathrm{ZnS}(0) / \mathrm{Ag}(30)$, while the deposition angle of $\mathrm{Ag}$ was maintained at $30^{\circ}$, Figure 7 (a). The reflectance value of $30.3 \%$ in the visible region was obtained for $i=30^{\circ}$ at $\lambda=800 \mathrm{~nm}$. This was followed by $i=45^{\circ}, 15^{\circ}, 60^{\circ}$ and $75^{\circ}$. The reflectance for other angles of incidence was $<20 \%$. The reflectance pattern had been altered compared to the values obtained in Figure 7 (a). The reflectance for $i=30^{\circ}$ in the infrared region reached $73 \%$ at $\lambda=2400 \mathrm{~nm}$. Other spectra attained maximum reflectance values $(41 \%-54.5 \%)$ in the infrared region at $\lambda=1978 \mathrm{~nm}$. There were sharp peaks in the wavelength range $350-450 \mathrm{~nm}$. These peaks showed the presence of monodispersed $\mathrm{ZnS}$ nanoparticle distribution. The reflectance values obtained on this sample indicates poor reflectance in the visible wavelengths. This was a good modification for use in transparent nanostructures. The high reflectance in the infrared wavelength implies that infrared transmittance was poor for this sample. In terms of thermal infrared control, the specimen should be aligned such that light is incident on it at $i=15^{\circ}$ in the visible region and at $i=30^{\circ}$ in the infrared region.

On increasing the angle of deposition of $\mathrm{ZnS}$ from $\mathrm{ZnS}(0) / \mathrm{Ag}(30)$ to $\mathrm{ZnS}(30) / \mathrm{Ag}(30)$ (Figure 7 (b), the reflectance values in the visible region was $<27 \%$. The spectra for $i=15^{\circ}$ had higher values in the visible wavelength followed by $i=30^{\circ}$. The spectra for $i=30^{\circ}$ had high reflectance values $(62.7 \%$ at $\lambda=2400 \mathrm{~nm})$ in the infrared wavelength. Other spectra had peak reflectance values in the range between $36.7 \%-51.9 \%$ at 1979 
$\mathrm{nm}$. The reflectance decreased with increase in angle of incident radiation from $i=15$ to 45,65 , and $75^{\circ}$. Low values of reflectance in the visible region meant that this sample has reciprocally high transmittance values to visible light.

When the angle of deposition of $\mathrm{ZnS}$ was adjusted to $60^{\circ}$ i.e. $\mathrm{ZnS}(60) / \mathrm{Ag}(30)$, Figure 7 (c), reflectance values for different angles of incidence in the visible region were $28.0 \%, 59.5 \%, 22.4 \%, 21.3 \%$ and $17.2 \%$ for $i=15^{\circ}, 30,45,65$, and $75^{\circ}$ respectively. While the reflectance in the infrared region, reflectance values ranged between $36.4 \%-57.9 \%$ for $i=15^{\circ}, 45.7 \%-80.3 \%$ for $i=30^{\circ}, 22.3 \%-52.7$ for $i=45^{\circ}, 20.5 \%-51.2 \%-51.2 \%$ for $i=60^{\circ}$ and $16.1 \%-34.0 \%$ for $i=75^{\circ}$. The reflectance for $i=30^{\circ}$ was higher than for $i=15^{\circ}$ in the visible wavelength. This implies that this sample was transparent to both visible light and highly reflective to infrared light. The physical significance of this sample was that it could be used in applications involving antireflectors or in the reflection of thermally energetic infrared radiation with tilted angles of incidence between for for $i=15^{\circ}$ to $i=30^{\circ}$.
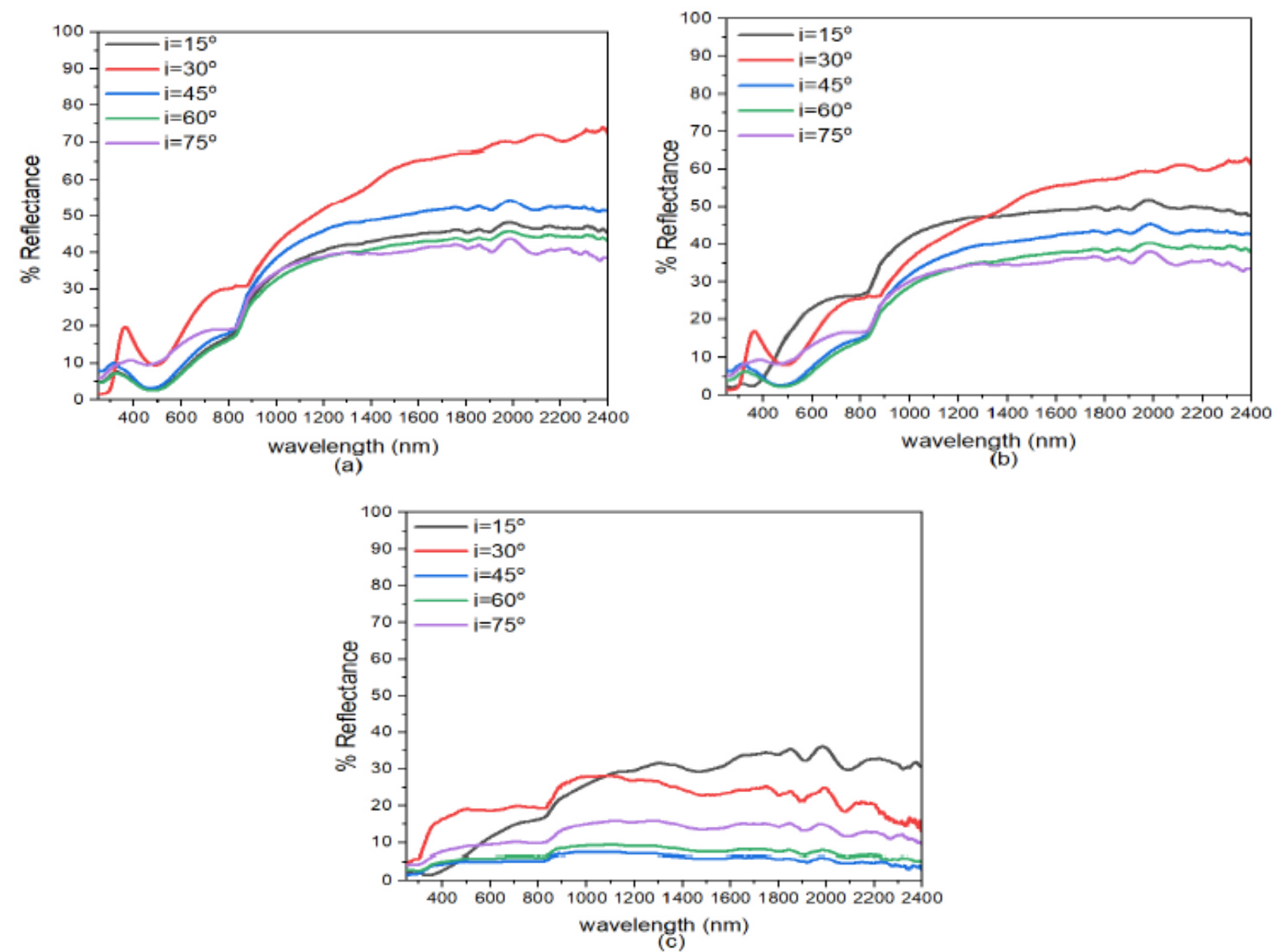

Figure 7. Reflectance spectra of $(10 \mathrm{~nm}) \mathrm{ZnS} / \mathrm{Ag}$ nanostructures. The silver nanoparticles were deposited at $30^{0}$ on glass substrate followed by ZnS at different deposition angles; (a) at $\left(0^{\circ}\right),(\mathrm{b})$ at $\left(30^{\circ}\right)$ and (c) at $\left(60^{\circ}\right)$

\subsection{Transmittance and reflectance spectra for $(10 \mathrm{~nm}) \mathrm{ZnS} / \mathrm{Ag}$ at different deposition angles}

Most of the spectrophotometric studies on multilayer structures involve the measurement of reflectance and transmittance to ascertain optical quality of the reflecting surfaces. This approach provides the opportunity to establish a correlation between deposition processes, conditions and optical parameters such as reflectance, transmitance and optical absorbance. When an electromagnetic radiation is incident on the surfaces of nanostructures such as Ag and ZnS, electrical oscillations of conducting electrons takes place on the surface of the metal. These electrical oscillations are called localized surface plasmons [47].

The excitation of surface plasmons by an external electrical field results in charge polarization on the metal surface. At resonance point (point at which frequency of applied field is equal to frequency of waves from electrical excitation), surface plasmon resonance occurs which leads to strong absorption or scattering of 
incident light. Surface plasmon absorption bands of Ag are in the visible and near infrared spectral regions. This is very useful for technological applications. When Zinc sulphide nanoparticles are subjected to the external electromagnetic field, coherent oscillations (surface Plasmon resonance) of the conduction electrons also occurs [48]. Surface plasmon effects are however, affected by several factors which include frequency of incident radiation, film thickness and formation of atomic islands on the surface of the dielectric substrate. Notebly, film thickness and deposition angle present a profound effect on spectral properties of thin film nanolayers. It is against this simple background that the Authors were prompted to carryout a comparison between reflectance and transmittance measurements on the samples.

The transmittance spectra of $(10 \mathrm{~nm}) \mathrm{ZnS} / \mathrm{Ag}$ decreased with increase in deposition angle of $\mathrm{ZnS}$ in the wavelength range between (480 nm - $1200 \mathrm{~nm}$ ), Figure 8 (a). In the wavelength range of $380 \mathrm{~nm}-520 \mathrm{~nm}$, the transmittance values were between $48 \%-56 \%$. The high transmittance of $\mathrm{ZnS} / \mathrm{Ag}$ nano multilayers was due to high refractive index of $\mathrm{ZnS}$ that enhanced antireflection of incident electromagnetic radiation [49] and [50]. In the infrared region, at about $\lambda=800 \mathrm{~nm}$, the transmittance was $<20 \%$ and then the transmittance decreased rapidly as the wavelength was increasing. In the visible region, reflectance values were low ranging between $5 \%$ to $32 \%$. The reflectance in the infrared wavelength increased from $\lambda=800 \mathrm{~nm}$ to $2200 \mathrm{~nm}$ to a reflectance value of $58 \%$ at $\lambda=2000 \mathrm{~nm}$.

The high transmittance in the visible spectrum is due to small thickness and relative homogeneity of the thin films at normal deposition angle of silver [51]. From the graph, there exist points which the researchers have referred to as equivalence points. These are points at which transmittance curves intersect the reflectance curves. These points occur in the wavelength range $\lambda=570-640 \mathrm{~nm}$. High reflectance in the infrared region signifies poor transmittance to thermal infrared radiation while the same samples have relatively average values values to transmittance of visible light.

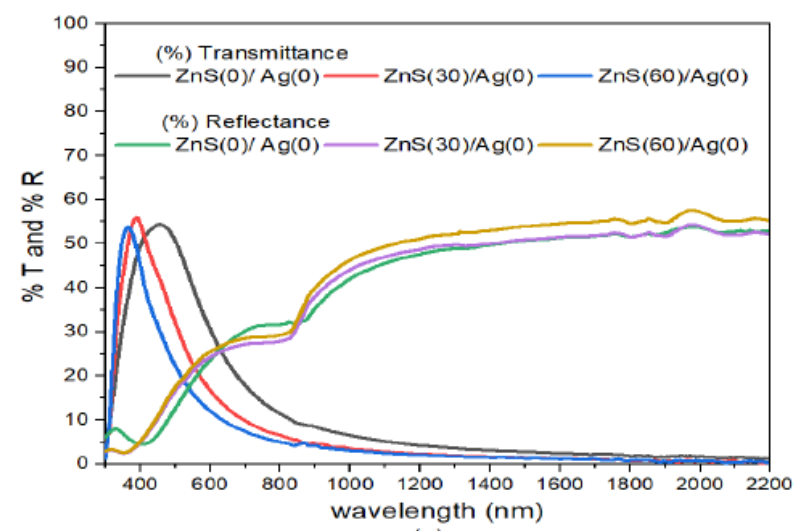

(a)

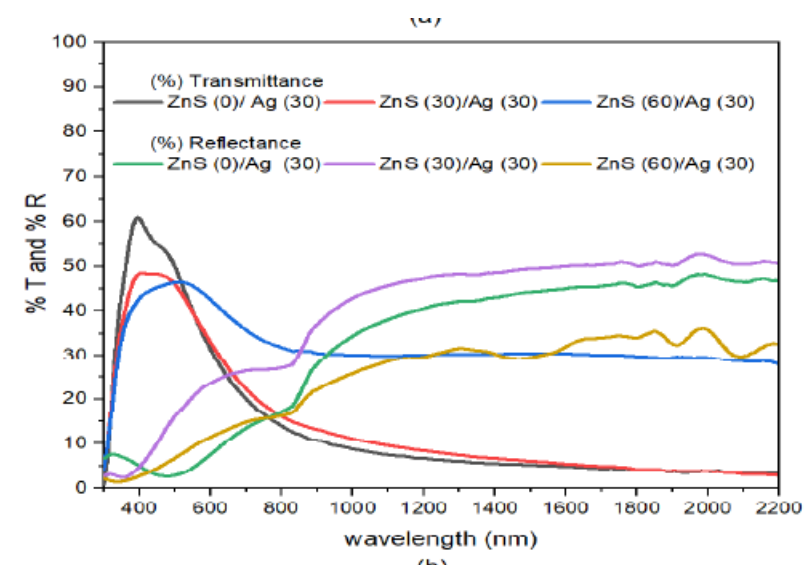

(b)

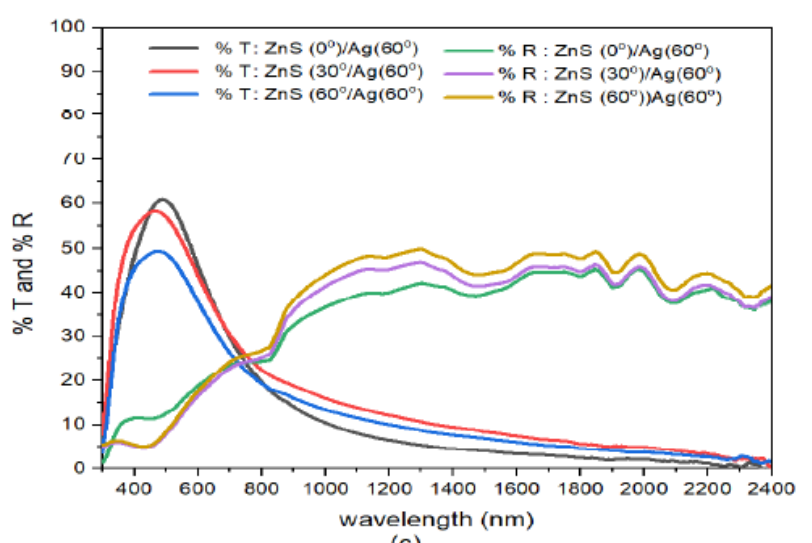

(c)

Figure 8. Reflectance and transmittance spectra of (10nm)ZnS/Ag nanostructures. (a) The deposition angle of $\mathrm{ZnS}$ was increased from $0^{\circ}$ to $60^{\circ}$ when the deposition angle of was fixed at $0^{\circ}$. (b) The deposition angle of ZnS was increased from $0^{\circ}$ to $60^{\circ}$ when the deposition angle of was fixed at $30^{\circ}$. (c) The deposition angle of $\mathrm{ZnS}$ was increased from $0^{\circ}$ to $60^{\circ}$ when the deposition angle of was fixed at $60^{\circ}$. 
The transmittance of the deposited films decreased with increase in deposition angle of $\mathrm{ZnS}$ in the $\mathrm{ZnS} / \mathrm{Ag}$ multilayer film in the visible region, Figure 8 (b). However, in the infrared region, transmittance increased with increase in deposition angle of $\mathrm{ZnS}$. The reflectance in the infrared wavelength decreased with increase in deposition angle of $\mathrm{ZnS}$ films. The equivalence point were shifted and spread in the wavelength between $620-830 \mathrm{~nm}$. This behaviour was also been reported in a recent study by [52].

At high deposition angle of $\mathrm{Ag}$ i.e. $\mathrm{ZnS} / \mathrm{Ag}(60)$ Figure 8 (c), the transmittance in the visible region increased considerably. However, transmittance decreased with increase in deposition angle of $\mathrm{ZnS}$ in the visible wavelengths. The transmission peaks at the wavelength of about $500 \mathrm{~nm}$ decreased with increase in deposition angle of $\mathrm{ZnS}$. Where us in the infrared region, transmittance increased with deposition angle of $\mathrm{ZnS}$. This shifted the equivalence point to about $\lambda=780 \mathrm{~nm}$. The physical shift in equivalence wavelength was due to high deposition angle of both zinc sulphide and silver films. The high deposition angle of Ag decreased the reflectance in the infrared region.

\subsection{Transmittance and reflectance spectra for $(7 \mathrm{~nm}) \mathrm{ZnS} / \mathrm{Ag}$ at different deposition angles}

The composite made by depositing Ag films normally followed by ZnS at different deposition angles Figure 9 (a) was characterised with high transmittance in the visible wavelengths and low transmittance in the infrared region. The optical transmittance increased with increase in deposition angle of $\mathrm{ZnS}$ in visible region. The transmission peaks in visible spectrum increased with the deposition angle of $\mathrm{ZnS}$. The transmission peaks decreased progressively towards the the long wavelengths i.e. $74 \%$ for $(7 \mathrm{~nm}) \mathrm{ZnS}(60 / \mathrm{Ag}(0), 68.7 \%$ for $(7 \mathrm{~nm}) \mathrm{ZnS}(30 / \mathrm{Ag}(0)$ and $65.9 \%$ for $(7 \mathrm{~nm}) \mathrm{ZnS}(0 / \mathrm{Ag}(0)$. At the wavelength $\lambda \geq 800 \mathrm{~nm}$, the transmittance was $<20 \%$. The reflectance of the nanostructures in the visible region decreases with increase in deposition angle of ZnS. It was observed from Figure 9 (a), that the reflectance values in the infrared wavelengths was lower than reflectance values in the visible wavelengths. Though the reflectance values of the samples were above average $(<50 \%)$ in the infrared region, the samples could reflect more infrared light than what they can transmit. On the other hand, visible transmission for the samples was fairly above $65 \%$ which is a good property for visibility.

Additionally, reflectance increased from visible wavelengths to near infrared region of electromagnetic spectrum. These results were so close in the infrared region. Though the deposition angle for $\mathrm{ZnS}$ was increased from $0^{\circ}$ to $60^{\circ}$, the spectral response to deposition angle of $\mathrm{ZnS}$ did not change much. This shows that Ag nanoparticles strongly influence the transmittance and reflectance of the $\mathrm{ZnS} / \mathrm{Ag}$ multilayer films. The reflectance of the samples in the visible region $(\lambda=400-800 \mathrm{~nm})$ was low and ranged between $24 \%-31 \%$ for the three deposition angles of $\mathrm{ZnS}$. Reflectance in the infrared region for $\lambda \geq 800 \mathrm{~nm}$ was fairly good (between $55 \%$ and $58 \%$ ). The transmittance in the visible spectrum was above average and ranged between $65 \%$ and $75 \%$, Figure 9 (a).

When the angle of deposition of $\mathrm{Ag}$ was increased from $\mathrm{ZnS} / \mathrm{Ag}(0)$ to $\mathrm{ZnS} / \mathrm{Ag}(30)$ (Figure 9 (b), the transmittance in the visible region increased with increase in deposition angle of ZnS. The transmission peaks in the visible spectrum were obtained at around $\lambda=421 \mathrm{~nm}$ with the following transmittance values: $65 \%$ for $\mathrm{ZnS}(0) / \mathrm{Ag}(30), 63 \%$ for $\mathrm{ZnS}(30) / \mathrm{Ag}(30)$ and $60 \%$ for $\mathrm{ZnS}(60) / \mathrm{Ag}(30)$. The transmittance decreased progressively from $34.4 \%$ at $\lambda=800 \mathrm{~nm}$ to $16.8 \%$ at $\lambda=2400 \mathrm{~nm}$. The reflectance in the visible region at $\lambda=800 \mathrm{~nm}$ was very low (ranged between $6.5 \%-22.2 \%$ ) and decreased with increase in deposition angle of $\mathrm{ZnS}$. The reflectance then increased toward the near infrared spectral region. Interference effects decreased with increase in deposition angle of ZnS. Further analysis of Figure 9 (b), revealed that the transmittance values were very close in the entire electromagnetic spectrum. This meant that the changes in deposition angle of $\mathrm{ZnS}$ had less impact on the optical transmittance of the electromagnetic radiation. In the infrared spectral wavelengths, the reflectance values for $\mathrm{ZnS}(0) / \mathrm{Ag}(30)$ and $\mathrm{ZnS}(30) / \mathrm{Ag}(30)$ were greater than the transmittance of $\mathrm{ZnS}(0) / \mathrm{Ag}(30), \mathrm{ZnS}(30) / \mathrm{Ag}(30)$ and $\mathrm{ZnS}(60) / \mathrm{Ag}(30)$. The equivalence points were located at around $886 \mathrm{~nm}$ and $1054 \mathrm{~nm}$ in the infrared spectral wavelength.

When the deposition angle of $\mathrm{Ag}$ nanoparticles in the composite was raised to $60^{\circ}$ i.e. from $\mathrm{ZnS} / \mathrm{Ag}(30)$ to $\mathrm{ZnS} / \mathrm{Ag}(60)$ Figure 9 (c), there were remarkable spectral characteristics both in the visible and infrared wavelengths. The transmittance in the visible wavelength decreased with increase in the deposition angle of $\mathrm{ZnS}$. The transmission peaks were observed in the wavelength range of $400 \mathrm{~nm}$ to $560 \mathrm{~nm}$. The transmission peaks for specimen $\mathrm{ZnS}(0) / \mathrm{Ag}(30), \mathrm{ZnS}(30) / \mathrm{Ag}(60)$ and $\mathrm{ZnS}(60) / \mathrm{Ag}(60)$ were at $62.0 \%, 53.3 \%$ and $45.0 \%$ 
respectively. At about $\lambda=734 \mathrm{~nm}$, the trend in transmittance changed towards the infrared spectral range. The transmittance increased with increase in deposition angle of ZnS. This implies that the samples were more transparent to infrared radiation at high deposition angles of $\mathrm{ZnS}$. Nevertheless, the transmittance of $\mathrm{ZnS}(60) / \mathrm{Ag}(60)$ in the infrared wavelength was higher than the transmittance in the visible region by $11 \%$. The reflectance spectra in the visible had low values of $18.6 \%, 15.6 \%$ and 13.6 for specimen $\mathrm{ZnS}(0) / \mathrm{Ag}(30)$, $\mathrm{ZnS}(30) / \mathrm{Ag}(60)$ and $\mathrm{ZnS}(60) / \mathrm{Ag}(60)$ respectively at $\lambda=800 \mathrm{~nm}$. The reflectance then increased toward the infrared region but dependent on deposition angle of $\mathrm{ZnS}$. The reflectance decreased with increase in deposition angle of $\mathrm{ZnS}$ and reflectance interference effects were observed in the infrared wavelength. High values of reflectance were obtained at $\lambda=1843.9 \mathrm{~nm}$ and they were as follows: $43.5 \%, 34.9 \%$ and $25.0 \%$ for $\mathrm{ZnS}(0) / \mathrm{Ag}(30), \mathrm{ZnS}(30) / \mathrm{Ag}(60)$ and $\mathrm{ZnS}(60) / \mathrm{Ag}(60)$ respectively.

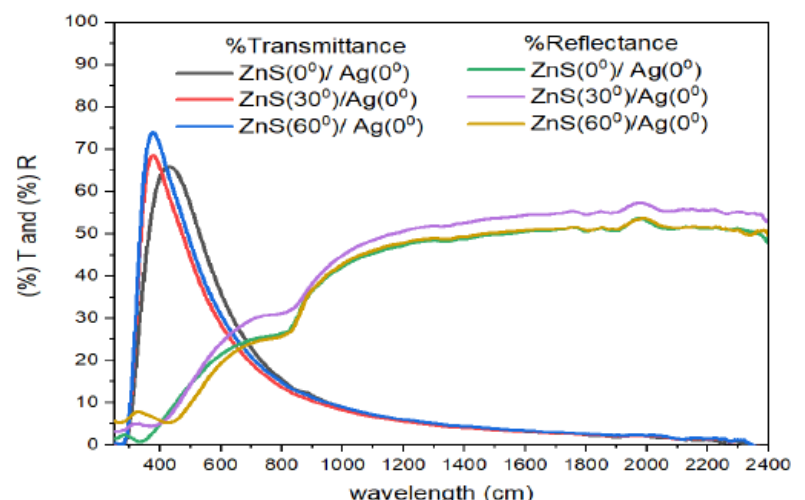

(a)

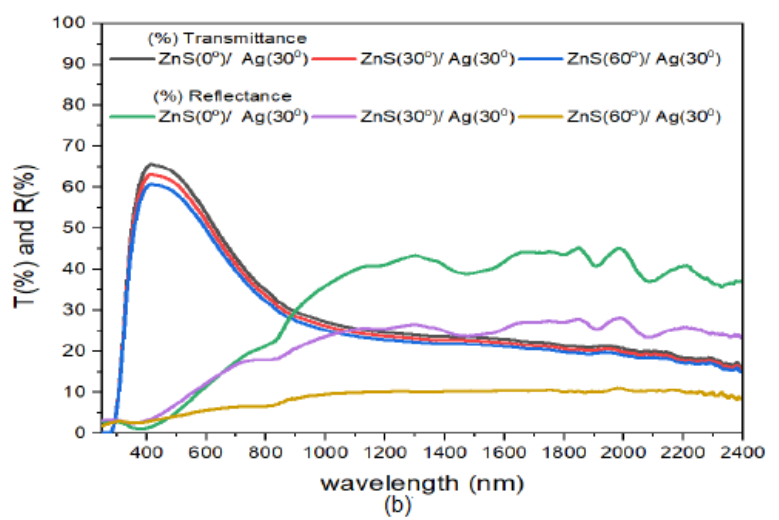

(b)

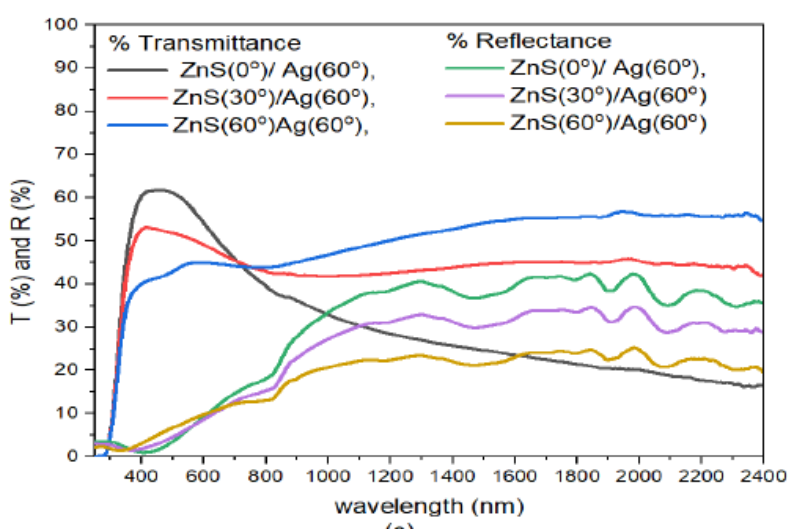

(c)

Figure 9. Reflectance and transmittance spectra of $(7 \mathrm{~nm}) \mathrm{ZnS} / \mathrm{Ag}$ nanostructures. (a) The deposition angle of $\mathrm{ZnS}$ was increased from $0^{\circ}$ to $60^{\circ}$ when the deposition angle of was fixed at $0^{\circ}$. (b) The deposition angle of ZnS was increased from $0^{\circ}$ to $60^{\circ}$ when the deposition angle of was fixed at $30^{\circ}$. (c) The deposition angle of $\mathrm{ZnS}$ was increased from $0^{\circ}$ to $60^{\circ}$ when the deposition angle of was fixed at $60^{\circ}$.

\subsection{Transmittance and reflectance spectra for $(4 \mathrm{~nm}) \mathrm{ZnS} / \mathrm{Ag}$ at different deposition angles}

The $(4 \mathrm{~nm}) \mathrm{ZnS} / \mathrm{Ag}$ nanostructures displayed quite different spectral characteristics compared to (7 $\mathrm{nm}) \mathrm{ZnS} / \mathrm{Ag}$ and $(10 \mathrm{~nm}) \mathrm{ZnS} / \mathrm{Ag}$ nanostructures. In Figure 10 (a), the optical transmittance values were higher than the reflctance values both in the visible and infrared spectral wavelengths. The transmittance peaks in the visible region exited at around $352-402 \mathrm{~nm}$ but increasing toward the short infrared wavelengths. At about $\lambda=1017 \mathrm{~nm}$, the transmittance of $(4 \mathrm{~nm}) \mathrm{ZnS}(0) / \mathrm{Ag}(0)$ continued to decrease however, the transmittance of $(4 \mathrm{~nm}) \mathrm{ZnS}(30) / \mathrm{Ag}(0)$ and $(4 \mathrm{~nm}) \mathrm{ZnS}(60) / \mathrm{Ag}(0)$ started to increase at about $790 \mathrm{~nm}$ towards the infrared wavelength. The reflectance of the specimens was very low $<12 \%$ at $800 \mathrm{~nm}$. The deposition angle of $\mathrm{ZnS}$ had little impact on the reflectance in the visible region but the reflectance in the infrared region decreased with increase in deposition angle of ZnS. Highest reflectance of $23 \%$ was observed at $\lambda=1995 \mathrm{~nm}$. The decrease in reflectance of $\mathrm{ZnS} / \mathrm{Ag}$ nanostructures may also be attributed to the formation of $\mathrm{ZnS}$ and $\mathrm{Ag}$ clusters or discontinuous Ag islands on glass substrate which enhanced transmittance or absorption of the visible light [53,54]. The $(4 \mathrm{~nm}) \mathrm{ZnS} / \mathrm{Ag}(0)$ nanostructures had near average optical transparency which qualifies them 
for potential applications in transparent windows and optoelectronic devices. The high transmittance at low deposition angles in the visible region is due to fairly smooth surface and relative homogeneity of the films [51]. The sharp decrease in transmittance was observed in the ultraviolet region and this was attributed to the light absorption by the dielectric layers.

When the deposition angle of Ag nanoparticles was increased to $30^{\circ}$, Figure 10 (b) the transmittance in the visible region increased with increase in deposition angle of Ag. However, the transmittance decreased with increase deposition angle of $\mathrm{ZnS}$. The transmission peaks progressively moved toward the infrared wavelength of the electromagnetic spectrum. The recorded peaks in transmittance were $62.0 \%, 66.8 \%$, and $53.5 \%$ for $\mathrm{ZnS}(0) / \mathrm{Ag}(30), \mathrm{ZnS}(30) / \mathrm{Ag}(30)$ and $\mathrm{ZnS}(60) / \mathrm{Ag}(30)$ respectively. At around $\lambda=1072 \mathrm{~nm}$, the transmittance tends to increase with the deposition angle of $\mathrm{ZnS}$. Nevertheless, the transmittance of $\mathrm{ZnS}(0) / \mathrm{Ag}(30)$ remained relatively high. The reflectance values in the visible were low ranging between $3 \%-9 \%$. A slight increase in reflectance was observed at $803 \mathrm{~nm}$. However, the reflectance decreased with increase in deposition angle of $\mathrm{ZnS}$. Highest reflectance in the infrared region was obtained at $\lambda=1985 \mathrm{~nm}$ as follows: $16.3 \%$ for $\mathrm{ZnS}(0) / \mathrm{Ag}(30), 11.2 \%$ for $\mathrm{ZnS}(30) / \mathrm{Ag}(30)$ and $6.1 \%$ for $\mathrm{ZnS}(60) / \mathrm{Ag}(30)$. The reflectance values were generally lower than the transmittance values. These samples were transparent to infrared and visible light wavelengths. However, they might not be suitable for thermal infrared control applications.
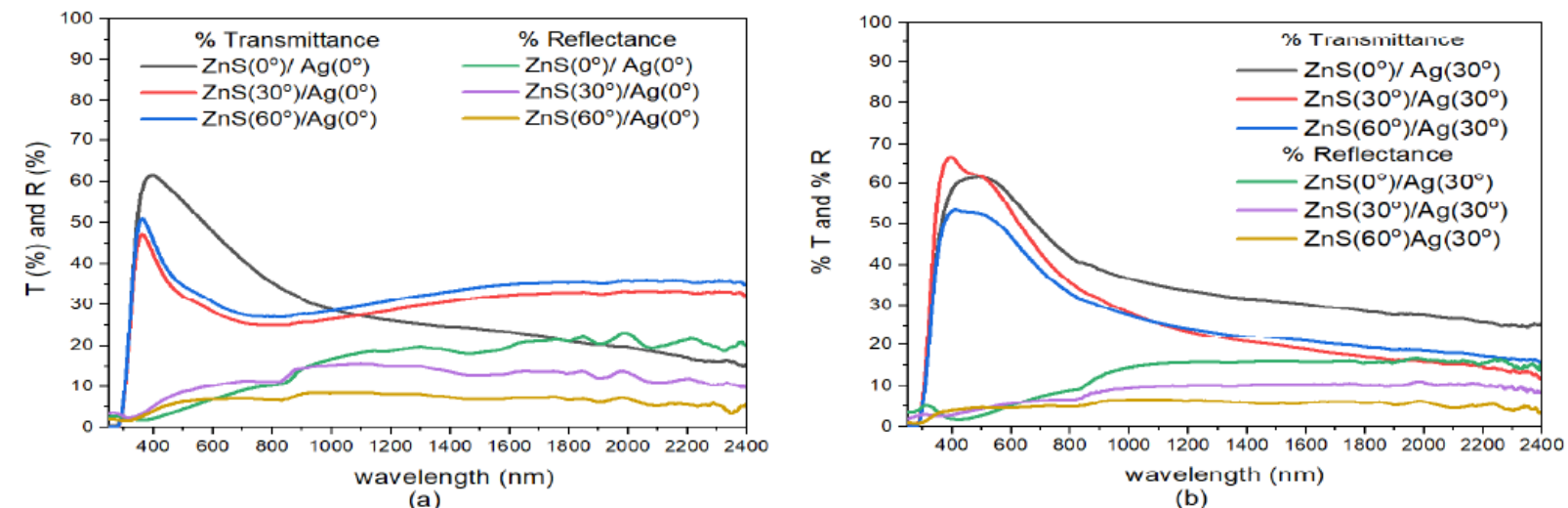

(a)

(b)

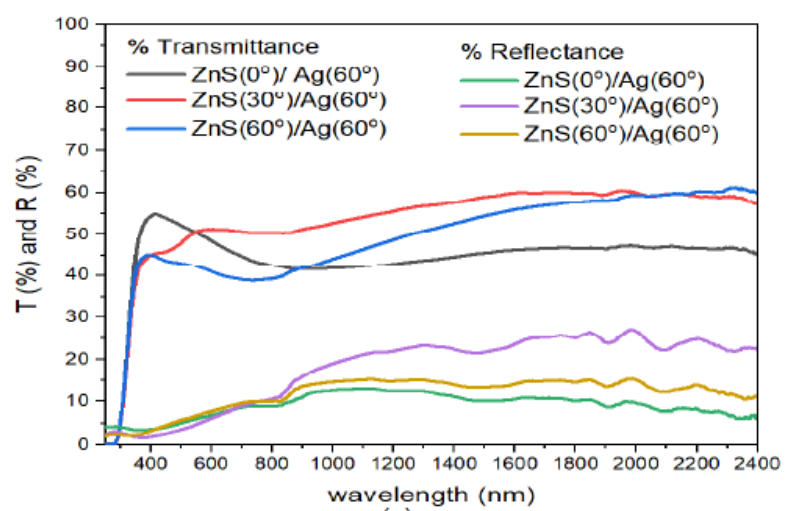

(c)

Figure 10. Reflectance and transmittance spectra of $(4 \mathrm{~nm}) \mathrm{ZnS} / \mathrm{Ag}$ nanostructures. (a) The deposition angle of $\mathrm{ZnS}$ was increased from $0^{\circ}$ to $60^{\circ}$ when the deposition angle of was fixed at $0^{\circ}$. (b) The deposition angle of ZnS was increased from $0^{\circ}$ to $60^{\circ}$ when the deposition angle of was fixed at $30^{\circ}$. (c) The deposition angle of $\mathrm{ZnS}$ was increased from $0^{\circ}$ to $60^{\circ}$ when the deposition angle of was fixed at $60^{\circ}$.

When the deposition of $\mathrm{Ag}$ nanoparticles was increased further to $60^{\circ}$ i.e. $\mathrm{ZnS}(30) / \operatorname{Ag}(60) 10$ (c), transmittance of the samples in the visible region decreased with increase in deposition angle of $\mathrm{ZnS}$. The transmission peaks in the visible were located between $381-580 \mathrm{~nm}$. The peak values for transmittance in this region were $55.0 \%, 51.5 \%$ and $45.3 \%$ for specimen $\mathrm{ZnS}(0) / \mathrm{Ag}(30), \mathrm{ZnS}(30) / \mathrm{Ag}(30)$ and $\mathrm{ZnS}(60) / \mathrm{Ag}(30)$ respectively. The transmittance values in infrared wavelength were higher than those in the visible region. The reflectance of the samples was very low and ranged between $3.3 \%-10.3 \%$ in the wavelength range $383-780 \mathrm{~nm}$. At around $800 \mathrm{~nm}$, the reflectance increased towards the infrared wavelengths. Highest 
reflectance was obtained at wavelength of $1983 \mathrm{~nm}$ for different specimens. The reflectance values obtained were as follows: $10.1 \%$ for $\mathrm{ZnS}(0) / \mathrm{Ag}(30), 27.3 \%$ for $\mathrm{ZnS}(30) / \mathrm{Ag}(30)$ and $15.5 \%$ for $\mathrm{ZnS}(60) / \mathrm{Ag}(30)$. The transmittance values were generally higher than the reflectance values in the entire electromagnetic spectrum. The significance of these results implies that these specimens are not desirable for use in thermal infrared control and anti-reflection applications.

\section{Conclusions}

The reflectance results of the multilayer structures of normally and obliquely evaporated $\mathrm{ZnS} / \mathrm{Ag}$ films on glass substrate show that the reflectance decreased with decrease in film thickness and deposition angle of $\mathrm{ZnS}$. However, the reflectance decreased with increase in deposition angle of silver metal films. By controlling the thickness and deposition angle, it is possible to design windows that are transparent to visible light and the same time opaque to near infrared photons. When the deposition angle of $\mathrm{ZnS}$ increased in the $\mathrm{ZnS} / \mathrm{Ag}$ multilayer, the reflectance decreased in the infrared region. The deposition of silver films at higher deposition angles suppressed reflectance in the visible spectral wavelength which is a desirable property for visible transparent optical structures. Therefore, it is recommended that silver films be deposited at higher deposition angles for high visibility. Considering the $(4 \mathrm{~nm}) \mathrm{ZnS} / \mathrm{Ag}$ nanostructures, the films had very low values of reflectance in both the visible and infrared regions. These nanostructures were transparent to the entire optical spectrum. Thermal regulation cannot be achieved with these films. Therefore, this composite was a poor heat mirror in the near infrared wavelength. The reflectance $(7 \mathrm{~nm}) \mathrm{ZnS}(0) / \operatorname{Ag}(0)$ and $(10 \mathrm{~nm}) \mathrm{ZnS}(0) / \operatorname{Ag}(0)$ at near normal incidence was around $33 \%$ in the visible region and over $50 \%$ in the infrared wavelength. Therefore, these structures can be considered as a transparent window materials for thermal infrared control. The reflectance of $(15 \mathrm{~nm}) \mathrm{ZnS} / \mathrm{Ag}$ was high both in the visible and infrared regions. Thus, these samples can be regarded as opaque to both visible light and infrared radiation. Therefore, they cannot be used as transparent heat mirror. The installation of reflective structures such as reflective mirrors should be done so as to achieve high transmittance (low reflectance) to visible light but high reflectance to infrared radiation energy. Thus for these nanostructures, the suitable orientation of the reflecting surface to the incoming electromagnetic radiation should at angle of incidence between $i=15^{\circ}$ and $30^{\circ}$. For angles of incidence $i>30^{\circ}$, reflectance values tend to decrease as the angle of incidence increases.

Acknowledgments: The Authors would like to acknowledge the financial and material support from SIDA (The Swedish International Cooperation Agency) through ISP (the International Science Programme, Uppsala University) and Uganda Independent Scholarships Trust Fund Board, Ministry of Education and Sports.

Author Contributions: All authors contributed equally to the writing of this paper. All authors read and approved the final manuscript.

Conflicts of Interest: "The authors declare no conflict of interest."

\section{References}

[1] Kaluba, V. S., Mohamad, K., \& Ferrer, P. (2020). Experimental and simulated performance of hot mirror coatings in a parabolic trough receiver. Applied Energy, 257, 114020, https://doi.org/10.1016/j.apenergy.2019.114020.

[2] Granqvist, C. G., Arvizu, M. A., Pehlivan, I. B., Qu, H. Y., Wen, R. T., \& Niklasson, G. A. (2018). Electrochromic materials and devices for energy efficiency and human comfort in buildings: A critical review. Electrochimica Acta, $259,1170-1182$.

[3] Chou, C. H., Lin, Y. T., Shinde, S., Huang, C. E., Wu, T. C., Lin, K. M., \& Hsiao, W. T. (2020). The development of a monitoring system for analyzing factors affecting film thickness in a sputtering process. Modern Physics Letters B, 34(07n09), 2040021, https:/ / doi.org/10.1142/S0217984920400217.

[4] Sinha, M. K., Mukherjee, S. K., Pathak, B., Paul, R. K., \& Barhai, P. K. (2006). Effect of deposition process parameters on resistivity of metal and alloy films deposited using anodic vacuum arc technique. Thin Solid Films, 515(4), $1753-1757$.

[5] Leftheriotis, G., Papaefthimiou, S., \& Yianoulis, P. (2000). Development of multilayer transparent conductive coatings. Solid State Ionics, 136, 655-661.

[6] Ivashchenko, M. M., Buryk, I. P., Opanasyuk, A. S., Nam, D., Cheong, H., Vaziev, J. G., \& Bibyk, V. V. (2015). Influence of deposition conditions on morphological, structural, optical and electro-physical properties of ZnSe films obtained by close-spaced vacuum sublimation. Materials Science in Semiconductor Processing, 36, 13-19.

[7] Morton, S. M., Silverstein, D. W., \& Jensen, L. (2011). Theoretical studies of plasmonics using electronic structure methods. Chemical Reviews, 111(6), 3962-3994. 
[8] Armstrong, S., Datta, P. K., \& Miles, R. W. (2002). Properties of zinc sulfur selenide deposited using a close-spaced sublimation method. Thin Solid Films, 403, 126-129.

[9] Erarslan, N., \& Güngör, T. (2019). The determination of the thickness and optical constants of the ZnO crystalline thin film by using pointwise unconstrained minimization algorithm. Mehmet Akif Ersoy University, http:/ /hdl.handle.net/11672/1658.

[10] Chambouleyron, I., \& Martínez, J. M. (2002). Optical properties of dielectric and semiconductor thin films. In Handbook of Thin Films (pp. 593-622). Academic Press.

[11] Garlisi, C., Trepci, E., Li, X., Al Sakkaf, R., Al-Ali, K., Nogueira, R. P., \& Palmisano, G. (2020). Multilayer thin film structures for multifunctional glass: self-cleaning, antireflective and energy-saving properties. Applied Energy, 264, 114697, https://doi.org/10.1016/j.apenergy.2020.114697.

[12] Cheng, J., Fan, D., Wang, H., Liu, B., Zhang, Y., \& Yan, H. (2003). Chemical bath deposition of crystalline ZnS thin films. Semiconductor Science and Technology, 18(7), 676, https://iopscience.iop.org/article/10.1088/0268-1242/18/7/313/pdf.

[13] Hemming, S., Kempkes, F., Van Der Braak, N., Dueck, T., \& Marissen, N. (2006, April). Greenhouse cooling by NIR-reflection. In International Symposium on Greenhouse Cooling 719 (pp. 97-106).

[14] Martin, P. M. (2009). Handbook of Deposition Technologies for Films and Coatings: Science, Applications and Technology. William Andrew.

[15] Moreno Santamaria, B., del Ama Gonzalo, F., Pinette, D., Gonzalez-Lezcano, R. A., Lauret Aguirregabiria, B., \& Hernandez Ramos, J. A. (2020). Application and validation of a dynamic energy simulation tool: A case study with water flow glazing envelope. Energies, 13(12), 3203, https:/ / doi.org/10.3390/en13123203.

[16] Casini, M. (2014). Smart windows for energy efficiency of buildings. In Proceedings of Second International Conference on Advances in Civil, Structural and Environmental EngineeringüACSEE, (pp. 273-281).

[17] Macleod, A. (2010). Oblique incidence and dielectric-coated metals. SVC Bulletin, 24-29.

[18] Abbasian, S., Moshaii, A., Vayghan, N. S., \& Nikkhah, M. (2017). Ag nanostructures produced by glancing angle deposition with remarkable refractive index sensitivity. Plasmonics, 12(3), 631-640.

[19] Han, Y. C., Lim, M. S., Park, J. H., \& Choi, K. C. (2013). ITO-free flexible organic light-emitting diode using $\mathrm{ZnS} / \mathrm{Ag} / \mathrm{MoO} 3$ anode incorporating a quasi-perfect Ag thin film. Organic Electronics, 14(12), 3437-3443.

[20] Dalapati, G. K., Kushwaha, A. K., Sharma, M., Suresh, V., Shannigrahi, S., Zhuk, S., \& Masudy-Panah, S. (2018). Transparent heat regulating (THR) materials and coatings for energy saving window applications: Impact of materials design, micro-structural, and interface quality on the THR performance. Progress in Materials Science, 95, 42-131.

[21] Jin, M., Chen, P., Boolchand, P., Rajagopalan, T., Chopra, K. L., Starbova, K., \& Starbov, N. (2008). Origin of giant photocontraction in obliquely deposited amorphous Ge $x$ Se 1- $x$ thin films and the intermediate phase. Physical Review B, 78(21), 214201, https://doi.org/10.1103/PhysRevB.78.214201.

[22] Hawkeye, M. M., \& Brett, M. J. (2007). Glancing angle deposition: Fabrication, properties, and applications of micro-and nanostructured thin films. Journal of Vacuum Science E Technology A: Vacuum, Surfaces, and Films, 25(5), 1317-1335.

[23] Robbie, K., \& Brett, M. J. (1997). Sculptured thin films and glancing angle deposition: Growth mechanics and applications. Journal of Vacuum Science \& Technology A: Vacuum, Surfaces, and Films, 15(3), 1460-1465.

[24] Liu, X., Cai, X., Mao, J., \& Jin, C. (2001). ZnS/Ag/ZnS nano-multilayer films for transparent electrodes in flat display application. Applied Surface Science, 183(1-2), 103-110.

[25] He, Y., Fu, J., \& Zhao, Y. (2014). Oblique angle deposition and its applications in plasmonics. Frontiers of Physics, 9(1), 47-59.

[26] Sobahan, K. M. A., Park, Y. J., \& Hwangbo, C. K. (2009). Effect of deposition angle on the optical and the structural properties of Ta2O5 thin films fabricated by using glancing angle deposition. Journal of the Korean Physical Society, 55(3), 1272-1277.

[27] Lyu, M., Lin, J., Krupczak, J., \& Shi, D. (2020). Light angle dependence of photothermal properties in oxide and porphyrin thin films for energy-efficient window applications. MRS Communications, 10(3), 439-448.

[28] Tanguier, J. L., Ali, A., Mahamat, A. D., Donnot, A., \& Drouet, J. M. (2021). Experimental determination of the thermal conductivity of new compressed clay formulations stabilized with gum arabic, measurement and impact on summer comfort. Journal of Materials Science Research and Reviews, 7(1), 1-14.

[29] Bwayo, E., \& Obwoya, S. K. (2014). Coefficient of thermal diffusivity of insulation brick developed from sawdust and clays. Journal of Ceramics, 2014, Article ID 861726, https:/ / doi.org/10.1155/2014/861726.

[30] Tikhonravov, A. V., Trubetskov, M. K., \& Amotchkina, T. V. (2006). Investigation of the effect of accumulation of thickness errors in optical coating production by broadband optical monitoring. Applied Optics, 45(27), 7026-7034. 
[31] Taylor, R. A., Hewakuruppu, Y., DeJarnette, D., \& Otanicar, T. P. (2016). Comparison of selective transmitters for solar thermal applications. Applied Optics, 55(14), 3829-3839.

[32] Drakopoulos, M., Snigirev, A., Snigireva, I., \& Schilling, J. (2005). X-ray high-resolution diffraction using refractive lenses. Applied Physics Letters, 86(1), 014102, http:/ /dx.doi.org/10.1063/1.1843282.

[33] Garlisi, C., Trepci, E., Li, X., Al Sakkaf, R., Al-Ali, K., Nogueira, R. P., \& Palmisano, G. (2020). Multilayer thin film structures for multifunctional glass: self-cleaning, antireflective and energy-saving properties. Applied Energy, 264, 114697, https://doi.org/10.1016/j.apenergy.2020.114697.

[34] Xiao, X., Dong, G., Xu, C., He, H., Qi, H., Fan, Z., \& Shao, J. (2008). Structure and optical properties of Nb2O5 sculptured thin films by glancing angle deposition. Applied Surface Science, 255(5), 2192-2195.

[35] Yildiz, A., Cansizoglu, H., Turkoz, M. U. S. T. A. F. A., Abdulrahman, R., Al-Hilo, A., Cansizoglu, M. F., \& Karabacak, T. (2015). Glancing angle deposited Al-doped $\mathrm{ZnO}$ nanostructures with different structural and optical properties. Thin Solid Films, 589, 764-769.

[36] Vrakatseli, V. E., Kalarakis, A. N., Kalampounias, A. G., Amanatides, E. K., \& Mataras, D. S. (2018). Glancing angle deposition effect on structure and light-induced wettability of RF-sputtered TiO2 thin films. Micromachines, 9(8), 389, https://doi.org/10.3390/mi9080389.

[37] Al Garni, S. E., Qasrawi, A. F., \& Khusayfan, N. M. (2021). Effects of polycrystalline GeO2 substrates on the structural, optical and electrical properties of ZnSe thin films. Physica Scripta, 7, 4168-4173.

[38] Studenikin, S. A., Golego, N., \& Cocivera, M. (1998). Optical and electrical properties of undoped ZnO films grown by spray pyrolysis of zinc nitrate solution. Journal of Applied Physics, 83(4), 2104-2111.

[39] Wu, M., Yu, S., He, L., Yang, L., \& Zhang, W. (2017). High quality transparent conductive Ag-based barium stannate multilayer flexible thin films. Scientific Reports, 7(1), https://doi.org/10.1038/s41598-017-00178-9.

[40] Han, Y. C., Lim, M. S., Park, J. H., \& Choi, K. C. (2013). ITO-free flexible organic light-emitting diode using $\mathrm{ZnS} / \mathrm{Ag} / \mathrm{MoO} 3$ anode incorporating a quasi-perfect Ag thin film. Organic Electronics, 14(12), 3437-3443.

[41] Wlodarski, M., Chodorow, U., Józwiak, S., Putkonen, M., Durejko, T., Sajavaara, T., \& Norek, M. (2019). Structural and optical characterization of ZnS ultrathin films prepared by low-temperature ALD from diethylzinc and 1.5-pentanedithiol after various annealing treatments. Materials, 12(19), 3212, https:// doi.org/10.3390/ma12193212.

[42] Zhou, C., \& Liu, H. (2017). A novel nanofibrous film chemosensor for highly selective and sensitive optical signaling of Zn 2+. Journal of the Brazilian Chemical Society, 28, 1947-1952.

[43] Liedtke, S., Grüner, C., Lotnyk, A., \& Rauschenbach, B. (2017). Glancing angle deposition of sculptured thin metal films at room temperature. Nanotechnology, 28(38), 385604, https://doi.org/10.1088/1361-6528/aa7a79 .

[44] Cho, K. H., Ahn, S. I., Lee, S. M., Choi, C. S., \& Choi, K. C. (2010). Surface plasmonic controllable enhanced emission from the intrachain and interchain excitons of a conjugated polymer. Applied Physics Letters, 97(19), 241, https://doi.org/10.1063/1.3508949.

[45] Hu, C., Guo, K., Li, Y., Gu, Z., Quan, J., Zhang, S., \& Zheng, W. (2019). Optical coatings of durability based on transition metal nitrides. Thin Solid Films, 688, 137339, https://doi.org/10.1016/j.tsf.2019.05.058.

[46] Sharma, V. K. (2012). Physics and Technology of Solar Energy: Volume 2: Photovoltaic and Solar Energy Materials Proceedings of the International Workshop on Physics of Solar Energy, New Delhi, India, November 24ÜDecember 6, 1986. Springer Science \& Business Media.

[47] Chalana, S. R., Ganesan, V., \& Mahadevan Pillai, V. P. (2015). Surface plasmon resonance in nanostructured Ag incorporated ZnS films. AIP Advances, 5(10), 107207, https://doi.org/10.1063/1.4933075.

[48] Venugopal, N., \& Mitra, A. (2013). Optical transparency of ZnO thin film using localized surface plasmons of Ag nanoislands. Optical Materials, 35(7), 1467-1476.

[49] Cho, H., Yun, C., Park, J. W., \& Yoo, S. (2009). Highly flexible organic light-emitting diodes based on ZnS/Ag/WO3 multilayer transparent electrodes. Organic Electronics, 10(6), 1163-1169.

[50] Liu, X., Cai, X., Mao, J., \& Jin, C. (2001). ZnS/Ag/ZnS nano-multilayer films for transparent electrodes in flat display application. Applied Surface Science, 183(1-2), 103-110.

[51] Osanyinlusi, O., Mukolu, A. I., \& Kana, M. Z. (2016). Structural and optical properties of $\mathrm{Al} / \mathrm{ZnO}$ thin films deposited by radio frequency sputtering. Materials Research Express, 3(9), 096401, https://doi.org/10.1088/2053-1591/3/9/096401.

[52] Nur-E-Alam, M., Vasiliev, M., \& Alameh, K. (2020). Dielectric/metal/dielectric (DMD) multilayers: growth and stability of ultra-thin metal layers for transparent heat regulation (THR). In Energy Saving Coating Materials (pp. 83-112). Elsevier.

[53] Hu, Y. M., Lin, C. W., \& Huang, J. C. A. (2006). Dependences of the Al thickness and annealing temperature on the structural, optical and electrical properties in ZnO/Al multilayers. Thin Solid Films, 497(1-2), 130-134. 
[54] Al-Ofi, H. H., Abd El-Raheem, M. M., Al-Baradi, A. M., \& Atta, A. A. (2012). Structural and optical properties of Al2ZnO4 thin films deposited by DC sputtering technique. Journal of Non-Oxide Glasses Vol, 3(3), 39-54.

(C) 2021 by the authors; licensee PSRP, Lahore, Pakistan. This article is an open access article distributed under the terms and conditions of the Creative Commons Attribution (CC-BY) license (http://creativecommons.org/licenses/by/4.0/). 